\title{
ESCLEROSE ENDOSCÓPICA DAS VARIZES ESOFÁGICAS APÓS TRATAMENTO CIRÚRGICO DA HIPERTENSÃO PORTAL EM PACIENTES COM ESQUISTOSSOMOSE HEPATOESPLÊNICA
}

DESCRITORES - Varizes esofágicas e gástricas. Escleroterapia. Hipertensão portal. Esquistossomose.

$\mathrm{Na}$ evolução da síndrome da hipertensão portal, a hemorragia conseqüente à ruptura das varizes esofágicas continua sendo a complicação mais temida. No nosso meio, o estudo da hipertensão portal assume importância pela alta incidência da esquistossomose mansônica, estimada em 3 a 4 milhões de pessoas parasitadas ${ }^{(12)}$. Com o programa de controle da esquistossomose, implantado no Brasil em 1975, foram tratados com esquistossomicidas cerca de 11 milhões de indivíduos, em especial nos Estados nordestinos ${ }^{(5)}$. Provavelmente, em decorrência deste programa, temos observado na última década, no Hospital das Clínicas da Faculdade de Medicina da Universidade de São Paulo, redução significativa de pacientes com esquistossomose na fase hepatoesplênica. E temos observado, também, que muitos destes pacientes nesta fase da doença apresentam associação com a hepatite viral.

Portadores da forma hepatoesplênica da esquistossomose mansônica, são normalmente jovens, com boa reserva funcional hepática e a mortalidade está diretamente relacionada à hemorragia pela ruptura das varizes esofágicas. $\mathrm{O}$ tratamento para a profilaxia da recidiva hemorrágica é, habitualmente, cirúrgico. Porém, com a difusão da escleroterapia endoscópica das varizes esofágicas, este método endoscópico, também tem sido empregado como opção terapêutica. Entretanto, tem-se observado na avaliação tardia que a recidiva das varizes esofágicas pode ocorrer em até $62,2 \%$ dos casos e recidiva hemorrágica em até $28,1 \%{ }^{(2,3)}$.

A cirurgia para hipertensão portal em esquistossomóticos é uma eventualidade muito comum no nosso meio, com indicação muito mais freqüente do que nos pacientes cirróticos. As recidivas hemorrágicas na fase tardia do pós-operatório podem ocorrer em até $66 \%$ dos casos $^{(11)}$. No nosso estudo ${ }^{(10)}$ comparativo em pacientes com esquistossomose com e sem cirurgia prévia para hipertensão portal, a escleroterapia das varizes hemorrágicas foi mais efetiva no primeiro grupo. $\mathrm{O}$ controle definitivo da hemorragia foi obtido em $97 \%$ dos pacientes previamente operados e em $72 \%$ dos pacientes sem cirurgia prévia. $\mathrm{O}$ número de sessões de escleroterapia para erradicação das varizes foi menor no primeiro grupo, assim como o índice de complicações. Estes resultados apresentaramse com diferença estatística significativa. E, analisando-se os tipos de cirurgia realizada, observou-se que aproximadamente $90 \%$ dos pacientes submeteram-se a esplenectomia simples ou associada a outras técnicas cirúrgicas. Assim, estes resultados, aparentemente, confirmam as conclusões já obtidas em décadas passadas de que a esplenectomia prévia melhora a eficácia da escleroterapia pela redução do fluxo portal ${ }^{(7)}$. Em especial nos pacientes esquistossomóticos, a artéria esplênica, assim como as veias esplênicas e porta, apresentam-se constantemente dilatadas. Este fato se deveria à acentuada 
esplenomegalia e, em conseqüência, verifica-se o aumento do fluxo portal. Assim sendo, PAES-ALVES et al. ${ }^{(8)}$ observaram redução de até $63 \%$ da pressão venosa portal após a esplenectomia, em pacientes com esquistossomose.

LEONARDI et al. ${ }^{(6)}$ preconizaram a escleroterapia com início 30 dias após a esplenectomia e desconexão ázigo-portal externa, em pacientes com esquistossomose hipatoesplênica, como medida profilática, objetivando erradicar as varizes remanescentes. PUGLIESE ${ }^{(9)}$, em estudo com 83 pacientes, iniciou com a escleroterapia 60 dias após a esplenectomia e desconexão ázigo-portal. No período de seguimento (46 meses) observou recidiva hemorrágica em dois pacientes, ainda na fase de escleroterapia e sem erradicação das varizes.

$\mathrm{O}$ artigo de FERRAZ et al. ${ }^{(4)}$, publicado neste número dos ARQUIVOS de GASTROENTEROLOGIA, enfatiza o tratamento combinado da cirurgia com a endoscopia. Embora seja estudo retrospectivo, demonstra a validade da complementação com escleroterapia na erradicação das varizes remanescentes. Estimava-se que o índice de recidiva hemorrágica pelas varizes deveria, portanto, ser menor em relação ao grupo não submetido a escleroterapia. Este fato não ocorreu, tendo em vista a erradicação das varizes em apenas $52,7 \%$ dos pacientes. Portanto, a quase metade dos pacientes restantes ficaram vulneráveis à recidiva hemorrágica.

Não há consenso em relação a escleroterapia profilática das varizes esofágicas após o tratamento cirúrgico da hipertensão portal. CÁPUA Jr e SZUTAN ${ }^{(1)}$ não concordam com a adoção rotineira desta medida terapêutica, justificando-se a escleroterapia apenas nos casos que ocorram a recidiva hemorrágica. Na realidade, como medida profilática é compreensível que muitos dos pacientes com varizes esofágicas remanescentes receberiam o tratamento endoscópico mesmo sem os riscos de recidiva hemorrágica. Este argumento poderia não se adequar à situação da realidade sócio-econômica a que pertencem os pacientes da casuística referida pelos autores do artigo publicado. Certamente, os pacientes nestas condições receberiam com o tratamento escleroterápico, uma proteção a mais contra a recidiva hemorrágica, porquanto a ocorrência desta complicação seria imprevisível. O ideal seria se dispuséssemos de acessórios como o "varipress", que permite a medida da pressão intravaricosa e os pacientes pudessem ter o acompanhamento endoscópico periódico. E havendo a elevação da pressão intravaricosa acima de $13 \mathrm{~mm} \mathrm{Hg}$ nos controles endoscópicos periódicos, a escleroterapia poderia ser indicada com precisão, porquanto acima da qual há riscos de ruptura varicosa.

Concordamos plenamente com os autores, quanto a necessidade da erradicação das varizes esofágicas como passo fundamental na prevenção de futuros episódios hemorrágicos. Vários fatores são influenciados na adesão dos pacientes a um programa de erradicação das varizes esofágicas através da escleroterapia. Um deles é a sensação dolorosa e o desconforto proporcionado pelo procedimento, e o outro é a necessidade de várias sessões no processo de erradicação das varizes. Acreditamos que a introdução da ligadura elástica no campo do tratamento endoscópico das varizes esofágicas, veio facilitar o procedimento, tornando-o mais efetivo com menor número de sessões e mais tolerável ao paciente.

$\mathrm{Na}$ fase aguda da hemorragia em esquistossomóticos, a nossa conduta atual é pela ligadura elástica das varizes como primeira opção. Caso esta não seja possível, efetuamos escleroterapia. Ambos os métodos substituem com vantagem o uso do balão esofágico e suas complicações. Entretanto, após o controle da hemorragia na fase aguda, os pacientes são encaminhados ao tratamento cirúrgico da hipertensão portal. A continuidade do tratamento endocópico é dada no pósoperatório ou, em paciente com contra-indicação cirúrgica, até a erradicação completa das varizes.

Paulo Sakai*

Sakai P. Endoscopic esophageal varices sclerotherapy post-surgical treatment for portal hypertension in patients with hepatosplenic schistosomiasis. Arq Gastroenterol 2001;38(2):81-83.

HEADINGS - Esophageal and gastric varices. Sclerotherapy. Hypertension, portal. Schistosomiasis.

\section{REFERÊNCIAS BIBLIOGRÁFICAS}

1. Cápua Jr A, Szutan LA. Desconexão ázigo-portal e esplenectomia mais escleroterapia no tratamento da hipertensão portal. In: Abrantes W, editor. Hipertensão portal - estado atual. Clin Bras Cir 1995;2(1):231-42.

2. Colleoni-Neto R. Avaliação tardia de doentes esquistossomóticos não operados após erradicação por escleroterapia endoscópica de varizes hemorrágicas do esôfago [tese de doutoramento]. São Paulo: Universidade Federal de São Paulo; 1998.
3. Cordeiro F. Variceal sclerosis in schistosomotic patients: a 5-year follow-up study. Gastrointest Endosc 1990;36:475-8.

4. Ferraz AAB, Lopes EP de A, Barros FM do R, Sette MJA, Arruda SMB, Ferraz EM. Esplenectomia com ligadura da veia gástrica esquerda e desvascularização da grande curvatura do estômago no tratamento da esquistossomose hepatoesplênica. É necessária a escleroterapia endoscópica pós-operatória? Arq Gastroenterol 2001;38:84-88

5. Lambertucci J, Serufo JC. Esquistossomose mansônica. In: Gayoto LC, editor Doenças do fígado e vias biliares. São Paulo: Atheneu; 2001. p.815-35. 
6. Leonardi LS, Boin IFS, Brandalise NA, Andreollo NA, Callejas NF, Andrade RG, Pareja JC. Results of the azigo-portal disconnection and splenectomy associated with sclerotherapy in schistosomiasis. ABCD Arq Bras Cir Dig 1988; 4:99-103.

7. MacBeth C. Treatment of oesophageal varices in portal hypertension by means of sclerozing injections. Br Med J 1955;2:877-80.

8. Paes-Alves CA, Alves AR, Abreu WN, Andrade AA. Hepatic artery hypertrophy and sinusoidal hypertension in advanced schistosomiasis. Gastroenterology 1977;72:126-8.

9. Pugliesi V. Desconexão ázigo-portal e esplenectomia associada à escleroterapia endoscópica no tratamento das varizes do esôfago na esquistossomose hepatoesplênica [tese de doutorado]. São Paulo: Faculdade de Medicina da Universidade de São Paulo; 1966.

10. Sakai P, Boaventura S, Ishioka S, Mies S, Sette H, Pinotti HW. Sclerotherapy of bleeding varices in schistosomiasis - comparative study in patients with and without previous surgery for portal hypertension. Endoscopy 1990;22:5-7.

11. Strauss E. Hipertensão portal esquistossomótica: análise evolutiva de intercorrências, dados endoscópicos e laboratoriais em estudo randomizado comparando três tipos de cirurgia [tese de livre-docência]. Ribeirão Preto: Faculdade de Medicina de Ribeirão Preto da Universidade de São Paulo: 1989.

12. World Health Organization. The control of schistosomiasis. Geneva: WHO; 1993. (WHO Technical Report Series nº 830). 